\title{
What abolishing the family would not do
}

Forthcoming in the Critical Review of International Social and Political Philosophy

\author{
Anca Gheaus \\ Law Department, Universitat Pompeu Fabra, Barcelona, Spain \\ agheaus@gmail.com
}

\begin{abstract}
Because families disrupt fair patterns of distribution and, in particular, equality of opportunity, egalitarians believe that the institution of the family needs to be defended at the bar of justice. In their recent book, Harry Brighouse and Adam Swift have argued that the moral gains of preserving the family outweigh its moral costs. Yet, I claim that the egalitarian case for abolishing the family has been over-stated due to a failure to consider how alternatives to the family would also disturb fair distributions and, in particular, equality of opportunity. Absent the family, children would continue to be exposed to care-givers of different levels of ability, investment in child-rearing and beneficial partiality. In addition, social mechanisms other than the family would lead to the accumulation of economic inequalities. Any kind of upbringing will fail to realise equality for reasons that go deeper than the family: our partiality and unequal abilities to nurture.
\end{abstract}

Keywords: family; equality of opportunity; upbringing; partiality; care

\section{Introduction}

There is an influential tradition of philosophers worrying that the institution of the family poses a challenge to distributive justice - most importantly (and most unavoidably) to the ideal of equality of opportunity. Following Harry Brighouse and Adam Swift's discussion of this problem in their book Family Values: The Ethics of Parent-Child Relationships (2014), I call it "the egalitarian challenge to the family". By "family" one should understand here the raising of children by a very small number of adults, who freely associate with each other and undertake long-term fiduciary responsibilities towards their biological, or adopted, children. 
Brighouse and Swift think that taking seriously the egalitarian challenge requires us to ask the question of "why it would be a bad idea to abolish the family" $(2014, \mathrm{p}$. 4). Their analysis seems to rely on the assumption that, absent the family and other things being equal, there would be significantly less disruption of distributive justice. Yet, such an assumption is too quick. In this paper I question it, and suggest - somewhat speculatively - that the real root of the problem is not the family. Rather, the root of those disruptions of equality the vehicle of which is, in existing societies, the family, is the combination of human partiality and our unequal interest in, and abilities to, nurture others - in particular, children. Since children's (even minimal) development depends on the nurturing they receive from some adults in the context of personal relationships, and since it is not possible to have all children raised by the same person, any upbringing will embody an element of brute luck for children when it comes to the quality of care they receive. The main claim of the paper is that any form of upbringing alternative to the family - whether or not designed with the aim of meeting children's needs as much as it is possible outside the family - will disturb equality, in particular equality of opportunity. Moreover, I raise doubts that equality of opportunity would be any more attainable in a society that rears its children outside the family - that is, in a society without families - than it is in a society with families properly reformed, along egalitarian lines.

This paper is grounded in the belief that partiality is universal, and likely to make its equality-disturbing appearance in any kind of upbringing. Partiality is probably impossible to eradicate and, moreover, desirable. Bernard Williams (1973) thought that one's integrity as an agent depends on allowing one's partial concerns to play an important role in guiding one's action. In other words, agency itself - and, with it, morality - may depend on permitting partiality. I think he was right; and in due course I shall elaborate on the thought that, as children, we need to experience partiality in the form of love if we are to flourish.

My argument, if correct, in no way distracts from the value of considering which kinds of family are legitimate given their impact on distributive justice - which is the real aim of Brighouse and Swift's enterprise. But it does bear on the usefulness of framing the discussion in terms of 
"abolishing the family" rather than merely reforming it. This is because talk of abolishing the family for the sake of equality may be a red herring (Macleod forthcoming): In order to answer the question of whether one has any reason to abolish the family in light of the egalitarian challenge and even in order to judge whether it is worth engaging with this question - one needs to know if alternative childrearing institutions would be significantly less likely to disrupt fair distributions than a (properly reformed) family. If they would not, then inequalities of opportunity between children raised by different parents cannot, even prima facie, be a good reason to abolish the family. Furthermore, talk of abolishing the family also risks to unnecessarily polarise the discussion and antagonise the public - including the academic, and, perhaps, even some of the philosophical, public - which is likely to be detrimental to much needed egalitarian reforms.

\section{The family and patterns of distributions - a brief overview}

The ideal of equal opportunity has been interpreted in very different ways, ranging from the belief that there should be a level playing field when it comes to social competition for desirable goods to the thought that we should all have the same chance to be well off, as long as we display the same level of responsible behaviour (Mason 2006). The family seems to prevent the full realisation of the principle of equal opportunity across the entire range of its possible interpretations. One's family largely determines one's access to a variety of resources that shape one's opportunities: people get jobs based on family relationships - like managing a family business - and have access to privileged sources of information and social connections that tilt the playing field in their favour. Parents shape children's future opportunities by influencing the cultivation of their talents and ambitions. Some parents buy private schooling for their children or use their superior knowledge to send them to better state schools, or they organise additional educational activities (like special holidays and trips to the museum). Micro-interactions between parents and children - such as dinner conversations and the reading of bedtime stories - directly shape children's values, abilities and aspirations. Last, but not least, different children have parents who 
are unequally good at bringing them up, which results in different opportunities to lead good lives as children and to develop into happy, resourceful and resilient adults.

John Rawls noted that "the principle of fair opportunity can be only imperfectly carried out, at least as long as the institution of the family exists." (Rawls, 1971, 74.) He thought that the existence of the family was inconsistent with the full realisation of the just society in which native talent and ambition alone determine individuals' opportunity for socially desirable positions. Yet, parents' level of income and education unavoidably influences the development of their children's talent, and therefore also the opportunities that their children will have, over time, to access wealth, income and positions of power and prestige. These inequalities cannot be justified, on Rawlsian terms, since they are not necessary in order to make the situation of the worst-off members of society as good as possible. Rawls has explicitly wondered, perhaps rhetorically: "Is the family to be abolished, then?" and gave his own, negative, reasoned answeri.

Not only Rawlsians, but also luck egalitarians should be bothered by the impact of the family on just distributions. James Fishkin (1983, p. 3) noted that three principles of justice that are widely endorsed by liberal egalitarians generate a trilemma. These principles demand that social positions be assigned on merit, that individuals enjoy equality of life chances, and that we respect the autonomy of the family. The last of these principles protects parents' freedom to rear their children as they judge fit (within the usual constraints imposed by morality). Yet, for the reasons mentioned above, parental freedom unavoidably translates into unequal life chances for children insofar as desirable resources - good jobs for instance - are distributed in a competitive manner and according to merit.

But the influence of the family on life chances is not limited to people's access to good jobs, positions of power or social prestige, nor - more generally - to goods whose distribution can, or should, be governed by competition. Egalitarians ought to be concerned about the family, and about child-rearing in general, while embracing any of a very wide range of assumptions about what goods, material or not, represent advantage, and how they are to be distributed (competitively or 
not). For instance, coming to value certain things may itself be a form of advantage, which has a non-competitive, as well as a competitive, dimension - since we could all have worthwhile conceptions of the good. As Veronique Munoz-Dared notes $(1999,41)$, the influence of the family goes beyond its influence on economic or social success, shaping who people are ${ }^{\mathrm{ii}}$ and how they think about a good life:

“as long as there are families, and hence deep inequalities between people's initial circumstances as regard class, social condition, cultivated attitudes to effort, to selfsacrifice, to autonomy, and so on, the ideal of equal realization of people's natural capacities and moral powers, including their capability to form, revise and pursue their own conception of the good, shall not be delivered." $(1999,40)$ [my emphasis]

\section{Familial relationship goods as the justification of the family}

So, given that the family shapes who we are and how we think about a good life as well as our chances to access this good, what, if anything, can justify it? Family Values offers an elaborate argument drawing on the value of parent-child intimacy to explain why, on the balance of reasons, we ought to preserve the family (in a reformed version), in spite of its unavoidable disruption of fairness. This is my own attempt to reconstruct their argument:

(1) The family inevitably disrupts just distributions - and as is, it perpetuates and exacerbates objectionable inequalities of income, status and various other non-material goods; even well regulated, it would undermine equality of opportunity.

(2) But the family is uniquely able to generate, via the parent-child intimacy, very important goods for both children and adults.

(3) The value indicated in (2) is more important than the disvalue indicated in (1).

(4) Therefore all things considered, reasons of equality of opportunity do not show that the family is morally unjustified.

Many people are convinced that some interpretation of the second premise is correct 
(Archard, manuscript). Yet, the authors of Family Values make the strongest case that I know of for this belief, by elaborating on the kinds of goods available only within (good) families, which they call "familial relationship goods". They also provide some support for the third premise and, mutatis mutandis, for the conclusion. In a nutshell the argument of the book is that the family provides both children and parents - who stand in a authoritative and intimate relationship with children - the good of meeting children's interests in a happy childhood and in physical, emotional, intellectual, and social development; the good of giving children and parents a sense of continuity with the past and the future; and, for adults, the good of playing well the parental role. Of these, the most important consideration is the meeting of children's interests. Proper care for children requires the continuity in care uniquely afforded by growing up in a family. On Brighouse and Swift's view, familial relationship goods are very weighty and cannot be substituted by other relationship goods, which makes them part of the distribuenda of justice. Abolishing the family would deprive all individuals - qua children and then qua adults - of goods to which they ought to have an opportunity.

This defence of the family is not meant to justify anything like the prerogatives that parents currently enjoy with respect to conferring advantage on to their children. Brighouse and Swift note that parents' freedom, for instance, to buy private education, or to bequest large amounts of wealth, cannot be justified by appeal to familial relationship goods. They also advocate egalitarian reforms to ensure that all children, and all adults who wish to parent and can parent well, are able to enjoy familial relationship goods. As I shall explain shortly, Brighouse and Swift do not believe that these reforms can write out all inequality of opportunity resulting from different children growing up in different families. But they argue, convincingly, that a world with perfect equality of opportunity yet devoid of the goods of parenting is worse than a world of families and imperfect equality of opportunity.

Indeed, Brighouse and Swift are not the first egalitarians to argue that the egalitarian challenge to the family can be addressed through a radical reform of the family, but they are more 
explicit than others that no amount of desirable reform can eliminate all inequality of opportunity resulting from childrearing in the family. Others thought that Fishkin's trilemma can be dissolved by rejecting a strong version of the autonomy of family principle. Peter Vallentyne and Morry Lipson (1989) make this case, noting that today's children will have the right to equal opportunities to pursue their conception of the good once they become adults, and hence today's adults ought to ensure that all children have an equal opportunity to develop the skills they will need for this pursuit. They argue we ought to abandon the principle that protects the current extent of parental freedom and, moreover, to engage in reforms such as the banning of certain adults from parenting, as well as providing state-funded training and information programs for would-be parents and numerous subsidised educational programs for children. Such reforms could indeed reduce the inequalities of opportunity between children raised in different families.

But there are good reasons to think, contra Vallentyne and Lipson, that even the properly reformed family will remain incompatible with equal opportunities for all to pursue their conception of the good. Assume 100\% inheritance taxes, no private education and all the reforms suggested by Vallentyne and Lipson. These measures would fall short of ensuring equally good childhoods to all children and equally favourable conditions for the development of their abilities and values. This is because, as Brighouse and Swift (2014) and Swift in earlier work (2003) noted - drawing on much sociological data - parental influence on children is to a large extent exercised through everyday micro-interactions that constitute the very substance of parent-child intimacy, such as the reading of bedtime stories and conversations over dinner. Moreover, as feminists working on the ethics of care have observed, the quality of care that children receive is constitutive of better or worse conditions for them to develop their abilities and conception of the good, including, for instance, a capacity to engage in, sustain and value caring relationships as adults (Gheaus 2009). Yet, it is most likely impossible to fully monitor and shape parent-child interactions - and even trying to do so would undermine the nurturing intimacy that justifies the family in the first place. So attempts to equalise the effects of family life on children's opportunities are likely to result in the much-dreaded 
phenomenon of levelling down (Brighouse and Swift 2014). Further, if micro-interactions are largely responsible for the transmission of advantage, this is probably to be explained, in part, through the fact that different parents have different levels of nurturing ability, views about good parenting and investment in their children. Some are more patient, attentive, affectionate, wise, or loving, or willing to dedicate themselves to childrearing than others. Short of assuming that we could equalise people's parenting abilities and investment in parenting, it is difficult to see how the reformed family could prevent inequalities in childrearing. So even the well-reformed family will remain, to some extent, incompatible with equality of opportunity unless all prospective parents become equally competent and invested in their children.

Moreover, Brighouse and Swift's defence of the family is vulnerable to the following worry: even if the family can uniquely promote the goods generated by parent-child intimacy, we know it does not always do so - that is, it does not generate familial relationships goods for all children. Some children grow up without parents or have parents unable or unwilling to sustain the intimate relationships that Brighouse and Swift deem valuable. They are the "worst off" when it comes to the goods of family life, and the defence of the family proposed by Brighouse and Swift is irrelevant to them: To these children, the inequalities generated even by a reformed family cannot be justified by appeal to the superior value of familial relationship goods, since these children do not get to enjoy such goods.

Brighouse and Swift may answer this last objection by stressing that they do not defend the family as is, but as it should be: effective in securing adequate parents to all children. Yet, bringing about such a transformation seems particularly hard to bring about because it would require not merely institutional change, but a profound transformation of people's personalities and of their everyday interactions with each other. The elimination of private schooling and inheritance may be politically difficult to achieve, but relatively easy to implement as long as there is a will - unlike the tackling of individuals' unequal ability and willingness to nurture children. It is likely that serious cases of child neglect and abuse can be drastically reduced, although probably not eliminated. But 
ensuring that all parents are adequate, let alone equally able to provide familial relationship goods, looks like a utopian ideal of a different order.

The case for keeping the family in the face of the egalitarian challenge may therefore seem to depend on whether it is possible to ensure that all children have parents. Before such a radical reform takes place, the inequalities of opportunities faced by children raised in different families remain unjustifiable to those children who are themselves negatively affected without the redeeming enjoyment of any familial relationship goods. Unless, as I explain below, the same inequalities would persist in the absence of the family: in that case the "worst off" of the family life could be told, by way of justification, that different childrearing practices would generate similar inequalities.

To sum up, even reformed, the family poses a complex egalitarian challenge: First, it continues to disturb equality of opportunity. Second, unless and until all children have adequate parents, it is hard to justify it to those children who are both raised by inadequate parents and are at the losing end of inequalities of opportunities caused by the family. Brighouse and Swift address only the first part of the challenge, and their answer concedes that equality of opportunity is inevitably the loser given the value of family relationships. Showing that equality of opportunity would be similarly disturbed in the absence of the family can also start to answer the second part.

\section{Egalitarian challenges to institutional child-rearing}

The family is not the source but merely a contingent vehicle of many inequalities of opportunities, whose deepest source lies with human partiality and adults' unequal abilities to nurture children. Moreover, even the current, unreformed, family is merely one of several such vehicles; in its absence, other institutions may promote more partiality-generated inequality then they do now.

I discuss three reasons that, jointly suggest that, in the absence of the family, childrearing arrangements will inevitably continue to generate morally objectionable inequalities ${ }^{\mathrm{iii}}$. They apply, 
albeit differently, to both adequate and inadequate institutional childrearing arrangements. These reasons are: the fact that different people who raise children will be differently capable to nurture them; the fact that different children will likely enjoy different levels of partiality from their childrearers, that is, some children will be liked and loved better than others; and the fact that people will, over their lifetime, tend to prefer certain individuals for associative purposes, thus allowing inequalities to cluster over time. Thus, even if material and cultural gifts were to be banned from institutional childrearing (to an extent to which they either cannot or ought not to be banned from the family), material transfers could happen between some child-rearers and their grown-up former charges. In addition, depriving people from an opportunity to rear children is likely to channel their partiality towards other individuals.

\section{Differently able and motivated Child-rearers}

Consider a world in which children are being reared in institutions rather than in families. You may imagine these institutions to be akin to permanent boarding schools, in which children are brought up by specialised employees - henceforth "childrearers". This is not the only alternative to the family. As Brighouse and Swift note, other possible ways of bringing up children include “Kibbutzim, in which child raising is shared between 'parents' and designated child-raising specialists" and "[c]ommunes in which a large group of adults collectively and jointly raises a group of children, with no adult thinking of herself as having any special responsibility for any particular child, and no child thinking of herself as the responsibility of any particular adult." (Brighouse and Swift 2014, 70-71). Yet, I assume that state-run institutional childrearing is the most likely setting of fully egalitarian childrearing, and so it provides the best test case for the point I make here.

Munoz-Darde is one of the few philosophers who engage in a systematic exercise of imagining what it would mean to abolish the family and rear children in something akin to "a very well-run orphanage". Comparing the family to institutional childrearing, she notes that "[t]he 
distinctive feature of a society in which children are raised in families is ... that children are looked after by different groups of elders, with different criteria and resources in each instance." (1999, pp. 44-45). By resources here she means material resources. Note that the last two features - different criteria and different material resources - characterise families as we have them now, but they are not crucial for the existence of the family. If we only lived in societies that were egalitarian, in both ethos and material distributions, it would be possible for children to grow up in families that would not disturb equality through differential levels of parental wealth. Sufficient socialisation of children outside the family and public discussion about good childrearing could perhaps generate (compliance with) general criteria of what constitutes good childrearing. Also, if children spent enough time in non-sectarian childrearing institutions they could have access to a variety of values and possible life choices. As for the last feature of the family identified by Munoz-Darde - that different elders rear different children - it is not in fact unique to the family. It would characterise institutional childrearing too, and this fact may be enough to create significant discrepancy in life opportunities. As already noted, much difference in upbringing may derive from the fact that different children are reared by different individuals with different aptitudes and willingness to invest themselves in childrearing. This means that childrearing outside the family may be just as disturbing of equality of opportunity as a properly reformed family.

I assume - importantly, if somewhat self-evidently - that, in order to qualify as childrearing any arrangement must enable children to survive and grow up into minimally functional social beings. Some children's most basic needs are for physical and regular interaction with other people and emotional and intellectual engagement with care-givers. For this reason, any childrearing will rely on some hands-on work done by people (rather than robots) ${ }^{\text {iv }}$. We know that babies whose needs for shelter, food and clothing are met by people, though only mechanically, and are never given any physical affection, emotional care and intellectual stimulation, will suffer from very high morbidity and mortality, fail to develop adequately, and often find it impossible to socialise. ${ }^{\mathrm{v}}$ This means that any upbringing that is humane and socially sustainable will require at least some 
personalised interaction between children and childrearers. Childrearing, however, that serves children's interests better, will go beyond this standard, allowing for plenty of interaction between children and child-rearers and encouraging the formation of deep personal bonds.

Further, I assume that childrearers will differ from each other with respect to how well they are able to nurture children. It may be easier to select out abusive or neglectful childrearers than it is to prevent abusive or neglectful parents from raising children. Therefore, by eliminating or significantly reducing neglect and abuse, it may be possible to ensure more equality between children brought up in institutions than we can ensure between children raised in a (reformed) family: the difference between the best and the worst childrearers might be smaller than that between the best and the worst parents. But significant differences would nevertheless exist: Amongst non-abusive or neglectful childrearers, and even amongst good childrearers, there is much variation in numerous skills that make children's lives go well and shape their future chances like attentiveness, patience, mindfulness, kindness, or an ability to take pleasure in children.

All these differences will shape children's opportunities in any institutional setting. In institutions designed with the modest aim of allowing children to survive and grow up, but with little interest for the quality of care beyond this standard, the differences between the best and the worst childrearers will likely be larger. Some, but not all, children will be lucky to have decent, or even adequate, childrearers. In institutions designed to advance all children's legitimate interests, childrearers will be, on average, much better, and the differences between them smaller; but allowing children to spend more time in personalised interaction with their childrearers and to form deeper relationships with them will amplify the effect of existing differences. Some of the personal qualities of people who raise us make a significant difference to our quality of life and to our present and future opportunities. Abolishing the family would not eliminate this source of unfairness.

Note that, if it was possible, through training, to turn people into adequate childrearers and therefore diminish some inequalities in upbringing, then this would advance equality independently 
of the issue of the existence of the family; ${ }^{\mathrm{vi}}$ therefore, if we could eliminate the inequalities stemming from unequal abilities to care in childrearing institutions, we could also do it within the family. Yet, more likely, any childrearing arrangement - familial or not, and adequate or not - will end up exposing children to differently resourceful and dedicated adults.

\section{Unequal Affection}

The second reason to doubt that the abolition of the family could result in an upbringing fully compatible with equality (of opportunity) also has to do with the nature of intimate interactions between children and childrearers. It is very likely that, as long as people - rather than robots - raise children in ways that rely on personalised interaction - rather than on the mechanical carrying out of tasks - some child-rearers would get to appreciate the individuality of some children, and become emotionally attached to them (as well as children to child-rearers). It is plausible that, unlike the minimally acceptable childrearing, adequate childrearing involves a significant measure of personalised relationships between children and their childrearers. This is in part for epistemic reasons - adequate childrearers are the advocates of children's interests and, therefore, need to know them well. ${ }^{\text {vii }}$ And, in part, it is because only within personalised relationships is it possible to meet children's need to be loved and appraised - both of which require that children feel understood in their particularity. Adequate institutional upbringing would give children this - although, presumably, to a lesser extent than good families and without the important benefits of continuity in care and higher intimacy afforded by family life.

The worry that children raised in institutions could not be loved or liked for their own individuality is often invoked as a main argument for preserving the family (its inegalitarian effects notwithstanding). Without endorsing this worry, Munoz-Darde (1998, pp. 47-8) expresses it well:

"in most cases children in families are treated as ends in themselves, they are cared for as the special person they are, intimate relationships and the language of affection connected with it constituting a force of individuation ... The thought would be that 
children need to be treated partially, as the singular person they are, in order to flourish. ... how probable is that, were the family to entirely disappear? Would not my fantasy of a generalized boarding school with teachers devoted to the individuality of each child vanish, were the state to have the sole control of the upbringing of children? Wouldn't it be the case that children would then be brought up not as ends in themselves, but as mere means for a collective purpose?"

Here our imagination may be unduly dominated by the bleak representations of orphanages in the collective imaginary - institutions where cold, detached adults perform, mechanically, a restrictive set of duties. However, note that even Dickens-inspired orphanages would most likely generate inequality of opportunity since every now and then a child would be lucky to be raised by an affectionate child-rearer; the difference in quality of life and future prospects between such a child and the rest would be huge. No orphanage in which children are able to survive could realise levelling down in this respect.

But there is of course no reason to think that a "well-run orphanage" would display this feature, nor is it unimaginable that children be raised in an institutional setting where their carers are humane and numerous enough to pay proper attention to their charges. Munoz-Darde probably echoes a general worry when she writes that, without the family, people would not "have the special ties of sentiment that in families parents often have towards their off-spring." "viii In a similar spirit, Brighouse and Swift note that the family is the "natural home of affectionate relationships" (Brighouse and Swift 2014, p. 4). The worry may be warranted in a strong interpretation - possibly, without the family, children and childrearers would tend not to forge emotional relationships that are as quite as deep and enduring as those between parents and children. But there is no reason to think that they would not forge nurturing emotional relationships at all. Why wouldn't they? Many people think that the biological connection between parents and children guarantees the "special" nature of the parent-child sentimental ties - in which case upbringing outside the biological family could not, in general, produce them (Brighouse and Swift do not seem to endorse this belief). Even 
if this was the case, sufficient ties of sentiment could be forged in childrearing institutions to allow some loving relationships between children and childrearers. To many people - presumably even more so to those who would choose to work as childrearers - children are particularly lovable individuals, and we know that non-biological parents can and do love their children. And, if the family did not exist, other settings would become the natural home of relationships based on love.

But if children and childrearers would be sufficiently close to each other to meet children's needs, then it is very likely that childrearers would tend to like and love the children in their charge differently. Loving parents, after all, are often known to like and even love some of their children better than others. This, at least, is what we know from anecdotal evidence and fiction, although it is probably a difficult fact for parents to admit. Some will worry that a parent who likes or loves one of her children better than others - or at least who lets this show - is, for this reason, not an adequate parent. It is an interesting question whether it would be, all-things-considered, desirable if childrearers raising children in institutions were always impartial towards their charges. Demanding impartiality from childrearers, and subjecting children to impartial upbringing, might in fact be undesirable for all parties.

But, desirable or not, it would in any case be unrealistic to assume that people engaged in long-term caring relationships can remain impartial towards those they are caring for. (This may be unrealistic even in the case of fiduciary relationships that are more episodic in nature, such as teaching and doctoring.) Just as we have no reason to assume that institutional childrearing will necessarily select the coldest, most emotionally detached of people, we have no reason to think that childrearers will be so different, morally speaking, from the rest of us so as to be able to always be impartial. Yet, if how much we are - and know we are - liked or loved as children makes a significant difference to how our lives go, including to our future opportunities, we have another reason to think that upbringing outside the family will continue to generate morally arbitrary inequality.

It is not parents' or childrearers' partiality as such that (keeping equal other things such as 
ability to confer advantage) translates into more inequalities in upbringing, but differences between the level of partiality that different parents or childrearers display. I do not see a reason to think that the partiality gap between the more partial and the less partial parents is wider than the partiality gap between the more partial and the less partial childrearers. One may think that an advantage of institutional childrearing - especiallyof the adequate kind - is that it assigns more than two childrearers to each child, thereby increasing every child's chances to be cared for by someone who gives the child loving affection ${ }^{\text {ix }}$. But this attractive feature can be secured while preserving the family, by introducing mandatory substantial non-parental care from an early age - a reform which, as I argued elsewhere, we have many reasons to support (Gheaus 2011).

Now, it is possible that universal, adequate, legitimate and sustainable institutional childrearing is not possible, at least by liberal lights. Adequate childrearing may require continuity in child-care, which in turn seems incompatible with occupational freedom for child-rearers. And universal institutional childrearing may result, over time, in state-enforced similarity, robbing individuals of their chance to experiment with different values and life style - at least, this is Munoz-Darde and, possibly, Rawls's worry. Maybe it would also rob children of adequate attention and love from adults. These consequences would depend on how resilient love and diversity really are. Even more plausible, and relevant to the purpose of this discussion, is that universal institutional childrearing might not be able to serve children's interests better than the family does (especially a properly reformed family.) However, this is not a challenge to the argument I offer here: inadequate childrearing institutions, we have seen, also display the above discussed sources of inequality between children. Even more than in adequate institutions, inadequate institutions would have children raised by differently able and motivated child-rearers; and some children would be loved (I assume that love is at least that resilient!) while others would not.

If any reasonably imaginable upbringing would expose children to people with unequal childrearing abilities and to unequal levels of affection, it is very likely that the family is merely a contingent vehicle of inequalities stemming from childrearing. In the absence of the family, other 
vehicles of generating unfair inequalities via human partiality, including institutional childrearing, would probably be more effective than they can be in a world of families.

\section{The Catholic Church (or something like it)}

Finally, it is a commonplace that the family also contributes to the inter-generational transmission of inequalities by allowing related individuals to accumulate, over time, large amounts of wealth. Since being well-off most often facilitates, and sometimes is a requirement for, being able to accumulate even more wealth, families allow wealth to cluster over time. What is true of wealth often applies to other desirable goods, such as valuable career opportunities or opportunities for personal development. Frequently, families are associations of individuals who are equally well or equally poorly connected to other well (or poorly) connected and educated people. Now, assume that in a society that lacks the family, and that is otherwise just, people are permitted to accumulate wealth over their life time, associate freely with others and make gifts, including gifts of high economic value, and bequests. And imagine that children were all raised in adequate institutions, giving them as-equal-as-possible - in light of the above-discussed constraints - starts in the competition for social goods, by providing them with the same quality of education and extracurricular activities. Depending on how competitive the distribution of goods would be in that society (which surely is a matter of justice independent from that of the existence of the family), individuals would be able to accumulate more or less wealth over the course of their life.

Since, throughout their lives, people would be free to associate with others, it is likely that they would form associations based in part on acquaintance and personal similarities - just as people do in existing societies. Sometimes caregivers and their now adult former charges would (continue to) be friends. And often the more enterprising, popular, skilled and motivated individuals would likely benefit from each other's support and thus enjoy increasingly better opportunities.

Most importantly, individuals would probably want to use the wealth they accumulate in order to advance some of their personal goals. Throughout their lives, and especially towards the 
end of their lives, accumulated wealth could turn into substantial gifts for those they love or for organisations and causes they support. Redistributive mechanisms will presumably regulate the extent to which free association will impact on equality of opportunity (and this is an issue orthogonal to that of the existence of the family). But, if partiality is both desirable and unavoidable - as I assume it is - redistributive mechanisms will not operate by trying to eliminate free association itself; any plausible conception of the exercise of legitimate political power must ensure that individuals have some space for personal relationships and some freedom to benefit those about whom they care most. In existing societies most individuals care predominantly about the wellbeing of their children. But, not having children "of their own", people living in societies without families would most likely be a lot more invested in their friendships than are people who raise families. In all likelihood, even in a society displaying an egalitarian ethos personal relationships would, and should, continue to matter to people as much as they matter now. With parenting unavailable, other relationships would take the central stage. Hence, people would gift and bequest wealth to their friends, sometimes younger ones. In this way, inequality could be perpetuated - and accumulated - across generations even in the absence of the family, thanks to the same partiality that perpetuates inequalities via familial relationships in the world as we know it.

In addition, because they could not raise children, people would probably channel more interest into various institutions meant to serve various causes. These institutions would become another important mechanism for the inter-generational reproduction of inequality. Even in a world of families, there are associational institutions other than the family that massively contribute to the inter-generational reproduction of inequality - including inequality of opportunity. An example of such existing institution - which, interestingly, functions for many people (priests, nuns and monks) as an alternative to the family - is the Catholic Church. Through an accumulation of gifts and the pooling of non-material resources over time, this institution has achieved a massive accumulation of wealth and power and therefore undermined equality of opportunity. (And there is no reason to think that, without various historical injustices such a development would have been unlikely.) 
Absent the family, associational institutions that capture individuals' allegiances - religious, like churches, but also non-religious, like clubs - would probably become even more significant vehicles of inequality of opportunities than they are now.

Of course, it may be that in a just world there would be equality-justified restrictions on how much wealth one can accumulate over a lifetime, on associational practices including professional networking, on gifts and bequests and on the scope of social competition for various goods. But, again, in this case - in a world of, say, functional socialism or communism - it is not clear that the family would really have more potential for disrupting equality than other permitted private associations that, in the absence of the family, could take a more central role in people's lives.

This is not to say that abolishing the family now, in the world as we have it, and rearing children in well-run, egalitarian institutions would not boost equality. But the boost would be due to the dismantling of large fortunes and social capital accumulated over generations and not to eliminating the features that make the family unavoidably equality-disrupting. This means that a similar boost of equality could be achieved without abolishing the family - simply by allowing public institutions to take over the education and socialisation of children to a significant extent, while at the same time implementing the usual economic measures advocated by egalitarians. It may be the case that abolishing the family is the most efficient short-cut to a more egalitarian world. But, if I am right, a world without the family will likely fall significantly short of full equality of opportunity, while a world with the family can get us as close to equality of opportunity as it is possible given human partiality and differences in nurturing abilities.

\section{Conclusion}

I have argued that human partiality and unequal abilities to nurture would likely disrupt equality (of opportunity) in any imaginable form of bringing up children - and, in particular in one that we can expect to meet, even minimally, children's current and developmental needs. Whatever else it could accomplish, the abolition of the family would not allow for the realisation of equality 
(of opportunity) since it is not the source of inequality.

If so, it is not obvious that what Brighouse and Swift (and many others) consider to be an egalitarian challenge to the family really is a challenge to the family. More likely, the challenge is to human partiality and unequal nurturing abilities. And, for better or worse, we are not likely to be able to change these facts. In this case, it seems misleading to frame the discussion of the muchneeded egalitarian reform of the family in terms of questioning its very existence. The defence proposed by Brighouse and Swift - that familial relationship goods are more important than equality of opportunity - may not be convincing to the "worst-off" of the family. But if a world of perfect equality of opportunity is not possible, it is not clear that the family's disruption of equality of opportunity is a reason for abolishing it - even a prima facie one. The matter depends on whether institutional childrearing would, in fact, disturb equality of opportunity significantly less than the (properly reformed) family. It is this last claim that my paper puts into question.

\section{Aknowledgements}

For comments and suggestions I am grateful to David Archard, Andree-Anne Cormier, Serena

Olsaretti, Liam Shields, Adam Swift, Christine Sypnowich and an anonymous referee of CRISPP.

\section{References}

Alstott, A. 2004. No exit: what parents owe society and what society owes parents. Oxford: Oxford University Press.

Archard, D. 2003. Children, Family and the State. London: Ashgate.

Archard, D. manuscript. "Why exactly is the family a problem for justice?", available at http://pldocs.org/docs/index-107473.html.

Brighouse, H., and Swift, A. 2014. Family Values: The Ethics of Parent-Child Relationships.

Princeton: Princeton University Press.

Fishkin, J. 1983. Justice, Equal Opportunity and the Family. New Haven: Yale University Press.

Gheaus, A. 2009. "How much of what matters can we redistribute? Love, justice and luck", Hypatia 
24 (4): 63-83.

Gheaus, A. 2011. “Arguments for Nonparental Care for Children”, Social Theory and Practice 37 (3): 483-509.

Mason, A. 2006. Levelling the Playing Field: The Idea of Equal Opportunity and its Place in Egalitarian Thought. Oxford: Oxford University Press.

Macleod, C. Forthcoming. “Equality and Family Values: Conflict or Harmony?”, Critical Review of International and Social Political Philosophy.

Munoz-Darde, V. 1998. "Rawls, Justice in the Family and Justice of the Family", Philosophical Quarterly 48 (192): 335-352.

Munoz-Darde, V. 1999. "Is the family to be abolished then?", Proceedings of Aristotelian Society 99 (1999), 37-56.

Nelson, C. A., Fox, N. A., and Zeanah, C. H. 2014. Romania's abandoned children: Deprivation, brain development, and the struggle for recovery. Cambridge, MA, and London: Harvard University Press.

Rawls, John. 1971. A Theory of Justice. Cambridge, Massachusetts: Harvard University Press.

Swift, A. 2003. How Not to be a Hypocrite: School Choice for the Morally Perplexed Parent.

London: Routledge.

Vallentyne, P. and Lipson, M. 1989. "Equal opportunity and the family", Public Affairs Quarterly 3 (4), pp.29-47.

Williams, B. 1973. “A Critique of Utilitarianism,” in Smart, J.J.C., and Bernard Williams (eds.) Utilitarianism: For and Against. Cambridge: Cambridge University Press, pp. 75-150.

Zeanah, N. H., Smyke, A.T., Koga, S. K., Carlson, E. and The Bucharest Early Intervention Project Core Group. 2005. "Attachment in Institutionalized and Community Children in Romania”, Child Development 76 (5), 1015-1028.

The St. Petersburg -USA Orphanage Research Team. 2009. The Effects of Early Social-Emotional and Relationship Experience on the Development of Young Orphanage Children. Monogr Soc Res 
Child Dev. 73(3) Wiley-Blackwell, doi:10.1111/j.1540-5834.2008.00483.x. Available online at:

\section{http://www.ncbi.nlm.nih.gov/pmc/articles/PMC2702123/pdf/nihms-84380.pdf.}

i

For discussions on Rawls on the family see Veronique Munoz-Darde (1998; 1999) and David Archard, (2003; manuscript). As Munoz-Darde writes, "...the effects of the family are so profound that its mere existence may severely impede the access of individuals to equal life chances. Moreover, this institution induces inequalities that are not beneficial to the badly off, and that are not the effect of a choice for which they can be held responsible." $(1999$, p. 37)

ii

She writes that the family affects "not only our opportunities in life, but the kind of person we become." While she iii

is not herself insisting on this point, this includes matters of character and personality.

Perhaps inequalities with respect to some goods - such as worthwhile conceptions of the good - would not be quite as large as they are in the absence of the family; but inequalities of wealth and income, that are most usually discussed by philosophers of the family, possibly would.

iv

The same assumptions about children's needs are made by Brighouse and Swift.

V

This is indicated by longitudinal studies on children growing up in Romanian orphanages (Zeanah et al. 2005,

Nelson, Fox and Zeanah 2014). Of course, the children in these studies often suffered various forms of abuse alongside emotional neglect. But other studies on institutional childrearing shows that emotional neglect by itself vi has very detrimental effects (The St. Petersburg - USA Orphanage Research Team. 2009).

Trainings for parents - both to prepare them to enter parenthood and to help them get better while at it - is also one vii of the measures proposed by Vallentyne and Lipson.

For an account of the instrumental value of parents having close knowledge of their children, see Anne Alstott (2004). Since these reasons have to do with child well-being, her point applies to the imaginary child-rearers, although they would not have the same opportunities to know the children in their charge as parents would. viii

Worry which she does not necessarily endorse herself (Munoz-Darde 1998, p. 44).

ix

I am grateful to an anonymous referee for alerting me to this possibility. 